\title{
Influence of machining parameters on part geometrical error in abrasive waterjet offset-mode turning
}

\author{
Mehdi Zohoor $^{\mathrm{a}}$, Iman Zohourkari ${ }^{\mathrm{b},{ }^{*}}$, Francesco Cacciatore ${ }^{\mathrm{c}}$, Massimiliano Annoni ${ }^{\mathrm{d}}$ \\ ${ }^{a}$ Faculty of Mechanical Engineering, K. N. Toosi University of Technology, Tehran, Iran, e-mail: mzohoor@kntu.ac.ir \\ ${ }^{b}$ Faculty of Mechanical Engineering, K. N. Toosi University of Technology, Tehran, Iran, e-mail: \\ i.zohourkari@dena.kntu.ac.ir \\ ${ }^{c}$ Department of Mechanical Engineering, Politecnico di Milano, Milan, Italy, e-mail: francesco.cacciatore@polimi.it \\ ${ }^{d}$ Department of Mechanical Engineering, Politecnico di Milano, Milan, Italy, e-mail: massimiliano.annoni@polimi.it \\ *Corresponding author, e-mail: i.zohourkari@dena.kntu.ac.ir, Tel.: +98 218406 3223; fax: +98 2188677274
}

\begin{abstract}
Geometrical error in abrasive waterjet turned parts is an important challenge towards the abrasive waterjet turning process commercialisation. A Systematic study has not been done yet to investigate the effects of process parameters on geometrical error in abrasive waterjet offset-mode turning. In this paper, a comprehensive study has been performed to investigate the influence of several machining parameters on the geometrical error (part diameter percent error) in turning AA2011-T4 aluminum alloy round bars. Water pressure, cutting head traverse speed, workpiece rotational speed, abrasive mass flow rate and depth of cut were considered as the main machining parameters in a five levels statistical experimental design. Basing on central composite rotatable design (CCRD), a total of 52 experiments was carried out. The main effects of the parameters and interactions among them were analyzed based on the analysis of variance (ANOVA) technique and the response contours for the part geometrical error were obtained using a quadratic regression model (i.e. RSM). The model predictions were found to be in good agreement with experimental data. Furthermore, among the significant parameters, pressure, depth of cut and traverse speed are the most influential parameters, with percent contribution of almost $25 \%$ each. Abrasive mass flow rate places as the least influential parameter with a percent contribution of $4 \%$.
\end{abstract}

Keywords Abrasive waterjet turning, Erosion, Machining, Response surface methodology, Geometrical error

\section{Introduction}

Abrasive waterjet turning (AWJT) is an innovative non-traditional machining technique which enables using advantages of waterjet in producing axisymmetric parts ${ }^{1-5}$. In the AWJT process, the workpiece revolves while the cutting head axially moves with a definite depth of cut to produce the required geometry (Figure 1). AWJT has superior benefits in comparison with a conventional turning. Material removal takes place by means of a flexible cutting tool (abrasive waterjet), so AWJT is less sensitive to the workpiece shape. It allows to machine at high depths of cut in one pass and offers fairly higher material removal rates (MRR), especially for hard-to-machine materials ${ }^{5,6}$. The process involves low cutting forces, so it is 
quite independent of the workpiece length-to-diameter ratio and therefore enables to turn long parts with small diameters ${ }^{7}$. Since abrasives have the capability to erode almost any materials, this process is ideally suitable for materials with low machinability such as ceramics, composites, glass, Titanium alloys and so on ${ }^{6,8,9}$. However, this process involves some challenges that limit its rapid growth and use in industries. Experimental investigations by pioneers of this technique, Ansari and Hashish, show that AWJT is a near-net shape machining process. ${ }^{1,2}$. It was reported that the final diameter of the turned part is usually more than the desired diameter because of the jet deflection and its instability ${ }^{10}$. However, from a visualization study, Ansari et al. ${ }^{11}$ pointed out how the abrasive waterjet does not undergo any significant radial deflection in the region where material removal takes place. Axinte et al. utilized AWJT as an efficient method to profile and dress grinding wheels and proved its technological and economical capability ${ }^{5}$. They could turn parts up to $\pm 0.1 \mathrm{~mm}$ accuracy. Studies on precision turning with AWJ showed that the accuracy of turned parts is affected by the jet trail-back and deflection ${ }^{10,12}$. Machining at high traverse speeds and depths of cut causes jet instability, which results in rougher surfaces, striation marks, poorer roundness and inconsistency in achieving the desired diameter.

Depending on the position of the nozzle/jet relative to the workpiece, Li et al. ${ }^{13}$ classified AWJT as "radial-mode" or "offset-mode". They evidenced the advantages of radial-mode turning over the offset-mode turning including more jet energy utilization, higher surface speeds, capability of nozzle tilt angle variations and smaller nozzle stand-off distances. These factors enable the process to provide higher material removal rates. However, controlling the depth of cut seems to be still an important challenge for radial-mode turning.

Some mathematical models capable to estimate the workpiece diameter continuous change in AWJT were also presented ${ }^{2,7,14-16}$. An analytical model suggested by Ansari and Hashish ${ }^{2}$ relates the volume swept by the combined specimen rotation and AWJ head traverse in the time unit (defined as the volume sweep rate (VSR)) to the material removal rate. This model could predict the workpiece final diameter for various sets of AWJT parameters. In spite of the continuous variation of impact angle during the workpiece diameter reduction, Hashish's analytical model does not consider impact angle modifications. An erosion based approach considering the varying local impact angle was presented by Manu and Babu ${ }^{7}$ to predict the workpiece final diameter. However, their model does not accurately predict the final diameter at various traverse speeds. Moreover, when the impact angle tends to zero, their model over estimates the removed material volume. By applying Hashish erosion model, Zohourkari and Zohoor presented a model with better estimation in terms of final diameter prediction ${ }^{15,17}$. Hlavac et al. ${ }^{16}$ presented a very comprehensive model, even if all the mentioned models do not consider the reduction of jet energy utilization at depths of cut lower than the jet diameter, the exact material flow stress and the focusing nozzle wear. Analytical models are still in their early stages and must be developed to become practical. Thus, statistical models which are capable to include the effects of controllable and uncontrollable parameters can be useful to model the AWJT process.

To improve the applicability of AWJT and to improve its accuracy, it is important to study the effects of operational parameters on the turned parts geometrical error and look for strategies to reduce it. Up to now, the lack of a systematic experimental study on AWJT able to show the effect of parameters on geometrical error is sensible, therefore, the effects of several machining parameters on the part geometrical error in abrasive waterjet offset-mode turning of AA2011-T4 are investigated in this paper. Five major machining parameters such as water pressure, cutting head traverse speed, workpiece rotational speed, abrasive mass flow rate and depth of cut were considered in a five-levels statistical experimental design. Based on central composite rotatable design (CCRD), a total of 52 experiments was carried out. The main effects of parameters and interactions among them were analyzed based on the 
analysis of variance (ANOVA) technique by Minitab $16{ }^{\circledR}$ software. The response contours for the geometrical error, defined as the part diameter percent error, were obtained using a quadratic regression. All parameters investigated in this research can be adjusted to the desired levels and their continual change is possible. It must be noted that there are other effective parameters such as orifice and focusing tube diameter, focusing tube length, abrasive material, size and shape, but the present study is devoted to act on the most controllable parameters in a standard waterjet machining center, keeping other parameters at a representative and significant level. This work aims to obtain a valuable understanding of parameters effects in the abrasive waterjet offset-mode turning process and presents a statistical model suitable to improve its accuracy.

\section{Abrasive waterjet turning strategy}

Based on the relative position of jet and workpiece, AWJT can be classified as radial-mode or offset-mode turning. Advantages of offset-mode turning compared to radial-mode turning are the ability of controlling the depth of cut ${ }^{13}$ and better surface quality ${ }^{1,4,18}$. Hence, AWJ offset-mode turning has been chosen for this study since it seems to be more suitable to meet industrial requirements. The schematic of the AWJ offset-mode turning is shown in Figure 1. In this process, the abrasive waterjet is adjusted in a desired position defining the nominal depth of cut $(D O C)$ and minimum distance between the focusing tube tip and the workpiece surface $(L c)$. The workpiece rotates at the rotational speed $N$, while the jet moves along the workpiece rotation axis at the traverse speed $u$ and erodes the workpiece surface in one pass to the final diameter $\left(D_{f}\right)$. Because of low cutting forces and no cutting tool wear, since the abrasive waterjet is the tool, it is possible to turn parts at high depths of cut in one pass ${ }^{6}$. Ideally, at the end of the part exposure to the jet, the jet becomes tangent to the surface of the workpiece. But, in practice, the final part diameter is more than the target diameter $\left(D_{t}\right)$, which introduces a geometrical error.
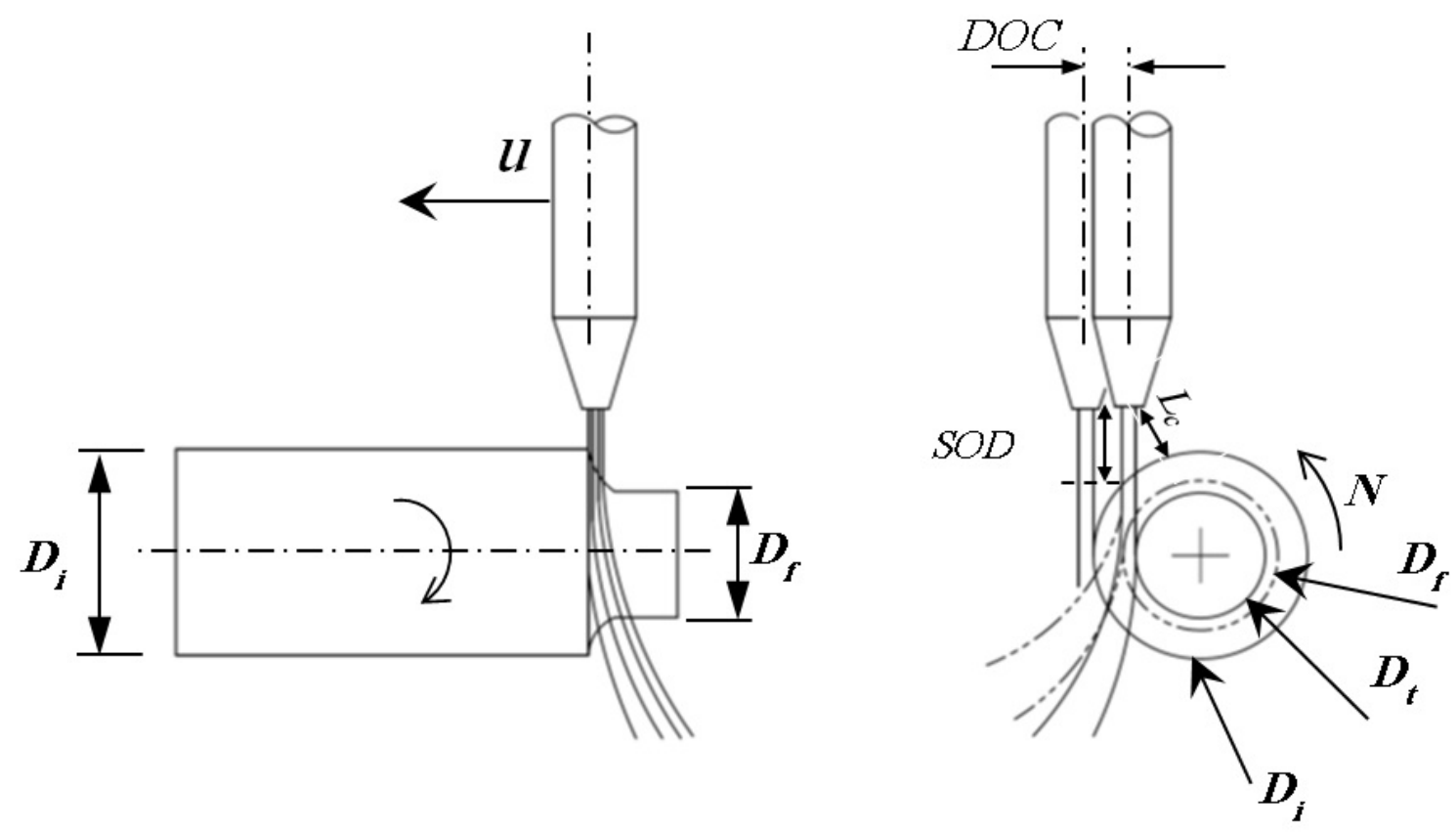

Figure 1 AWJ offset-mode turning process schematic

\section{Experiments}


The AWJT experimental apparatus was prepared by applying an AWJ machine (Tecnocut 5axis handling system with a Flow 9XV-S $380 \mathrm{MPa}$ pump) that is equipped with a custombuilt lathe with maximum rotational speed equal to $1000 \mathrm{rpm}$ (Figure 2).

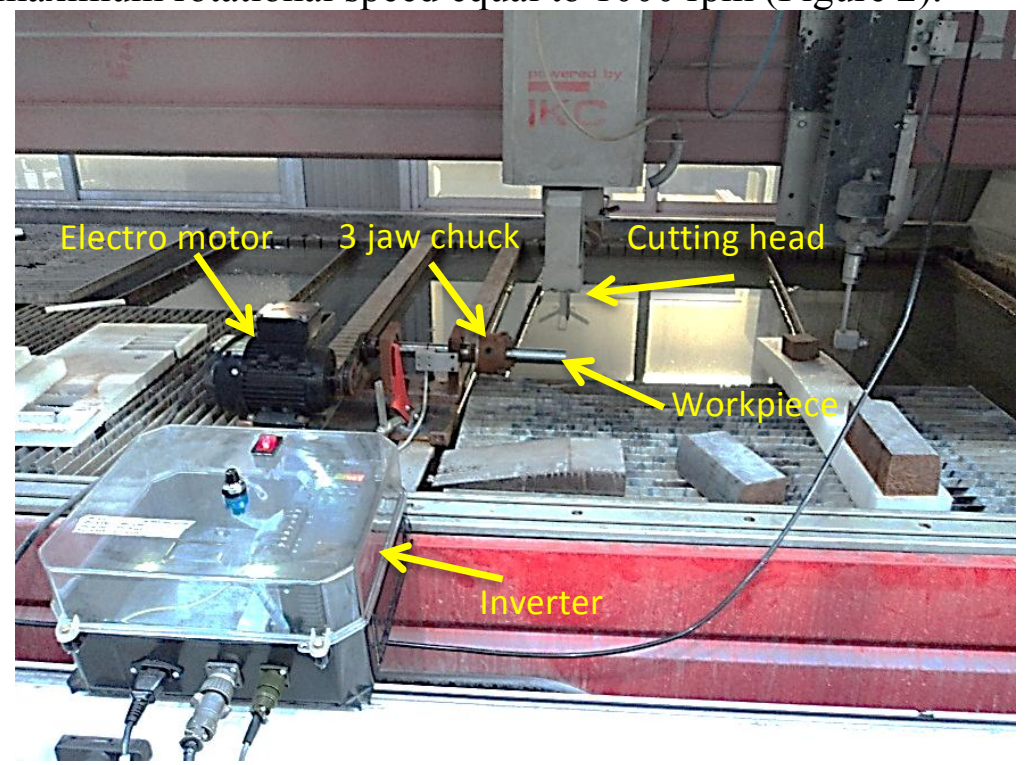

Figure 2 The experimental set-up for abrasive waterjet turning

$30 \mathrm{~mm}$ diameter AA2011-T4 circular bars were selected for this study. All the parts were cut to a $10 \mathrm{~cm}$ length and carefully cleaned with ethanol alcohol. The material composition of AA2011-T4 is given in Table 1.

Table 1 AA2011-T4 composition

\begin{tabular}{llllllll}
\hline & Aluminum & Bismuth & Copper & Iron & Lead & Silicon & Zinc \\
\hline AA2011-T4 & $93.7 \%$ & $0.2 \%$ & $5 \%$ & $0.5 \%$ & $0.2 \%$ & $0.2 \%$ & $0.2 \%$ \\
\hline
\end{tabular}

Based on previous researches by Hlavac et al. ${ }^{19-22}$, it is possible to assume that abrasives shape and size change due to their fragmentation while mixing and accelerating in the AWJ cutting head. This phenomenon depends on several parameters such as pressure, abrasive mass flow rate, orifice size, mixing chamber inner shape and focusing tube length and internal diameter. Since the abrasives size and shapes involved with the machining process have been kept constant at a significant industrial level, their effects were not investigated in this study. Mesh \#80 GMA Australian Garnet was used for all the experiments (Figure 3). A standard $0.3 \mathrm{~mm}$ diameter orifice and a standard $1.02 \mathrm{~mm}$ diameter focusing tube were used for all the tests.

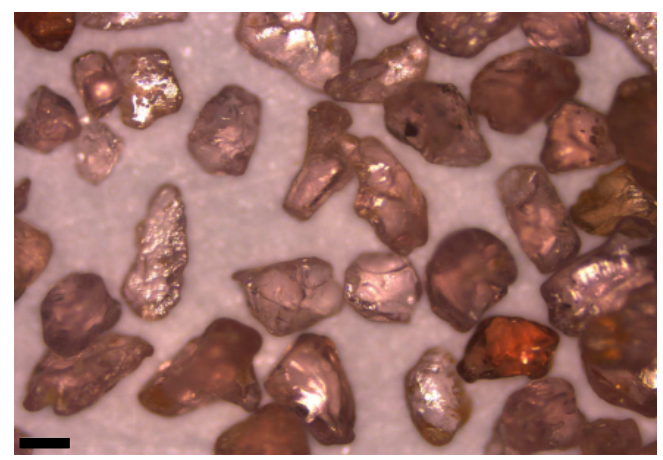


Figure 3 Image of the mesh \#80 GMA Australian Garnet used for the experiments taken by Alicona InfiniteFocus ${ }^{\circledR}$

\subsection{DOC adjustment}

To obtain the required workpiece geometry, it is important to accurately adjust the $D O C$. The reference system applied to set the $D O C$ at each experimental run has been defined by carrying out an accurate workpiece alignment procedure allowing the jet traverse line to be parallel to the workpiece axis and the jet to be tangent to the workpiece surface. Low water pressure has been used during such a procedure in order to obtain a very thin and coherent jet. After the DOC adjustment, the distance between the focusing tube tip and the workpiece surface $(L c)$ was set to $1 \mathrm{~mm}$ to avoid collision between.

\subsection{Experimental design}

The ranges of the selected factors, i.e. water pressure $(P)$, cutting head traverse speed $(u)$, workpiece rotational speed $(N)$, abrasive mass flow rate $\left(m_{a}\right)$ and depth of cut $(D O C)$, were identified during preliminary experiments using a "one factor at a time" methodology with respect to acceptable geometrical error, material removal rate and surface quality. Then the selected factors were organised in central composite rotatable design a CCRD scheme in five levels each. CCRD is an effective design able to handle linear, quadratic, and interaction terms in statistical modeling of processes ${ }^{23}$. CCRDs schemes include three sets of design points that are corner points $\left(n_{\mathrm{F}}=2^{k}\right)$, axial points $\left(n_{\mathrm{a}}=2 k\right)$ and center points $\left(n_{\mathrm{c}}\right)$, where $k$ is the number of process parameters. $k=5$ in the present case, so $n_{\mathrm{F}}$ and $n_{\mathrm{a}}$ are equal to respectively 32 and 10 . In order to consider the experiments pure error, it is common to perform some replicated experiments at the center point $\left(n_{\mathrm{c}}\right) .10$ center points were added to the experiments in this case.

The distance of the axial points from the center point is determined by the $\alpha$ value (put a reference here). For a CCRD, $\alpha=n_{\mathrm{F}}{ }^{1 / 4}$. According to the number of factors in this study ( $k=$ $5), \alpha=2.378$ and a total of 52 experiments was designed to perform.

The experimental factors are given in Table 2, where their coded and uncoded values are reported. Coding factors is an important step in response-surface analysis to allow a direct comparison of the factors weight on the process response ${ }^{23,24}$. Thus, higher and lower levels of the corner points were respectively coded with +1 and -1 ; the center points were coded with 0 and higher and lower levels of axial points were coded to $+\alpha$ and $-\alpha$ correspondingly. The linear relationships between the coded and the actual factors values are given in Eqs. from (1-a) to (1-e).

$$
\begin{aligned}
& P_{\text {coded }}=2\left(\frac{P-P_{0}}{P_{\text {high }}-P_{\text {low }}}\right)=0.02(P-250) \\
& u_{\text {coded }}=2\left(\frac{u-u_{0}}{u_{\text {high }}-u_{\text {low }}}\right)=0.4(u-5) \\
& N_{\text {coded }}=2\left(\frac{N-N_{0}}{N_{\text {high }}-N_{\text {low }}}\right)=0.01(N-400) \\
& m_{a_{\text {coded }}}=2\left(\frac{m_{a}-m_{a_{0}}}{m_{a_{\text {high }}-m_{a_{\text {low }}}}}\right)=0.685\left(m_{a}-5.24\right)
\end{aligned}
$$




$$
\begin{aligned}
& N_{\text {coded }}=2\left(\frac{N-N_{0}}{N_{\text {high }}-N_{\text {low }}}\right)=0.01(N-400) \\
& D O C_{\text {coded }}=2\left(\frac{D O C-D O C_{0}}{D O C_{\text {high }}-D O C_{\text {low }}}\right)=(D O C-3)
\end{aligned}
$$

Subscripts "high" and "low" represent the higher and lower levels of corner points and subscript " 0 " indicates the center point.

The initial and final diameters, respectively $D_{i}$ and $D_{f}$, were measured by means of a Zeiss Prismo 5 HTG VAST coordinate measuring machine (Figure 4) and the geometrical error $G E$, defined as the part diameter percent error, was calculated according to Eq. 2.

$$
G E=\frac{D_{t}-D_{f}}{D_{t}} \times 100
$$

\begin{tabular}{|c|c|c|c|c|c|c|c|}
\hline Process parameters & Symbol & Unit & $\begin{array}{c}\text { Lower } \\
\text { axial } \\
\text { point }\end{array}$ & $\begin{array}{c}\text { Lower } \\
\text { corner } \\
\text { point }\end{array}$ & $\begin{array}{c}\text { Middle } \\
\text { level }\end{array}$ & $\begin{array}{l}\text { Higher } \\
\text { corner } \\
\text { point }\end{array}$ & $\begin{array}{c}\text { Higher } \\
\text { axial } \\
\text { point }\end{array}$ \\
\hline & & & level 1 & level 2 & level 3 & level 4 & level 5 \\
\hline Coded factors & - & - & -2.378 & -1 & 0 & +1 & +2.378 \\
\hline Water pressure & $P$ & $\mathrm{MPa}$ & 130 & 200 & 250 & 300 & 370 \\
\hline $\begin{array}{c}\text { Cutting head traverse } \\
\text { speed }\end{array}$ & $u$ & $\mathrm{~mm} / \mathrm{min}$ & 0.3 & 3 & 5 & 7 & 9.8 \\
\hline $\begin{array}{c}\text { Workpiece rotational } \\
\text { speed }\end{array}$ & $N$ & $\mathrm{rpm}$ & 160 & 300 & 400 & 500 & 640 \\
\hline Abrasive mass flow rate & $m_{a}$ & $\mathrm{~g} / \mathrm{s}$ & 1.77 & 3.78 & 5.24 & 6.70 & 8.71 \\
\hline Depth of cut & $D O C$ & $\mathrm{~mm}$ & 0.6 & 2 & 3 & 4 & 5.4 \\
\hline
\end{tabular}

Table 2 Variable factors of the AWJT experimental campaign

\subsubsection{Response surface methodology}

Response Surface Methodology (RSM) is a statistical approach to find a mathematical form of the relationship among the process responses and the process parameters using statistical and mathematical techniques ${ }^{23,25-27}$. The mathematical equation stating the relationship between the AWJT process parameters and the geometrical error response can be expressed as:

$G E=f\left(x_{1}, x_{2}, x_{3}, x_{4}, x_{5}\right)+\varepsilon$

where $f$ is the response function and $x_{1}, x_{2}, x_{3}, x_{4}, x_{5}$ are respectively water pressure $(P)$, cutting head traverse speed $(u)$, workpiece rotational speed $(N)$, abrasive mass flow rate $\left(\dot{m}_{a}\right)$ and depth of cut $(D O C)$ and $\varepsilon$ is the error term. The response function $(f)$ is unknown and RSM has the ability to approximate it by a suitable polynomial. A second-order polynomial has been chosen due to its ability to model curvatures in the response surfaces as expressed in Eq. 4.

$\eta=\beta_{0}+\sum_{i=1}^{k} \beta_{i} x_{i}+\sum_{i=1}^{k} \beta_{i i} x_{i}{ }^{2}+\sum \sum_{i<j=2}^{k} \beta_{i j} x_{i} x_{j}$

where $\eta$ is the approximated response and $\beta_{i j}$ are the regression coefficients. The coefficients are found by using the least squares method and the linear regression analysis ${ }^{23}$. To obtain significant parameters, an analysis of variance is carried out. It must be concluded that 
confidence intervals for selecting significant parameters are typically fixed at the $95 \%$ confidence level ${ }^{28}$.

\section{Results and discussions}

\subsection{Statistical modeling of part geometrical error}

Abrasive waterjet turned parts obtained from planned experiment (i.e. 32 corner points $\left(n_{\mathrm{F}}=\right.$ 32), 10 center points $\left(n_{\mathrm{c}}=10\right)$ and 10 axial points $\left.\left(n_{\mathrm{a}}=10\right)\right)$ are shown in Figure 4.
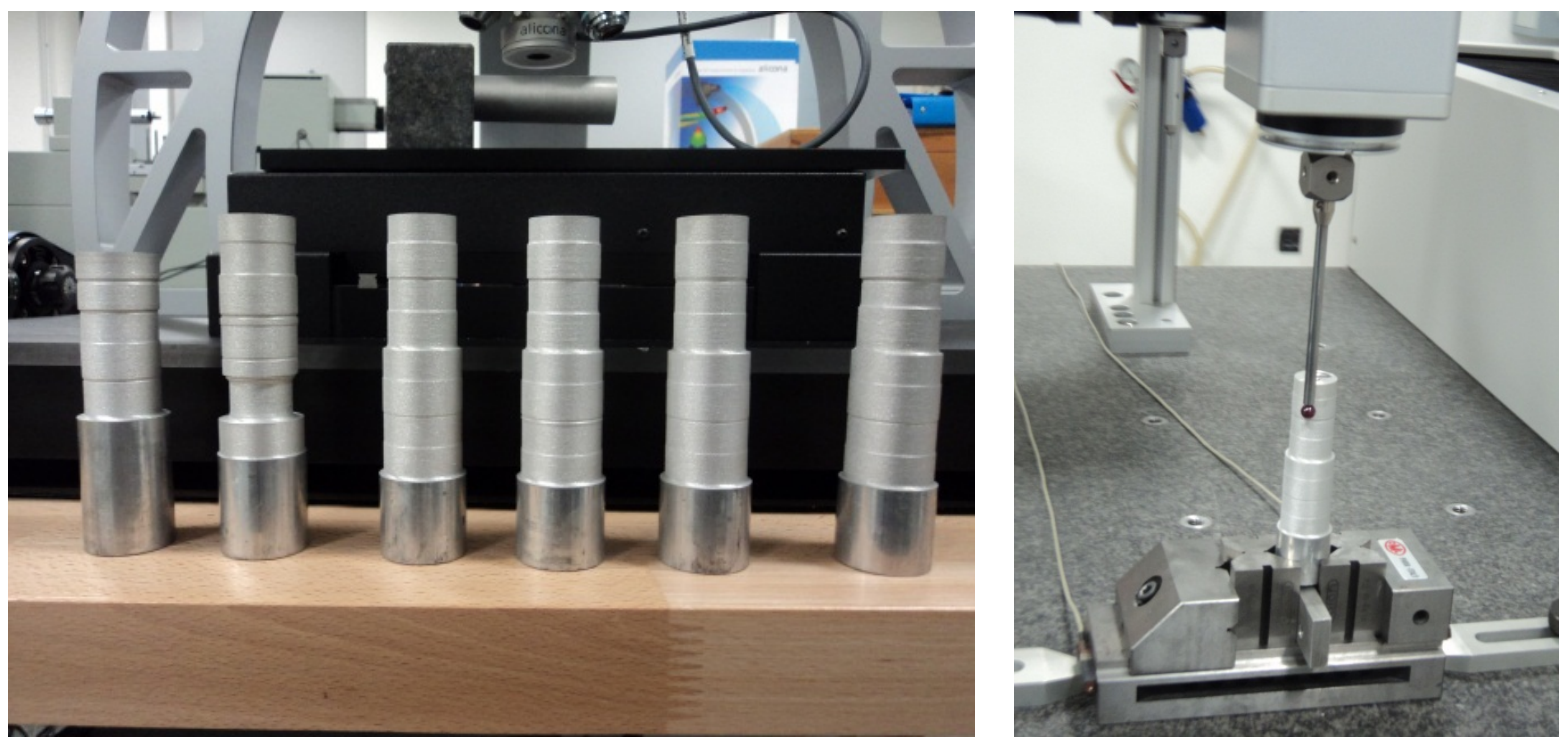

Figure 4 (a) Abrasive waterjet turned parts, (b) Measurement of parts final diameter by the Zeiss Prismo 5 HTG VAST CMM

According to the model defined by Eq. 2, a statistical analysis was accomplished considering the part geometrical error as process response. The ANOVA results for the geometrical error have been shown in Table 3. As shown in this table, it is possible to conclude that the secondorder regression model is significant, since its respective $p$-value is sufficiently less than 0.05 . Moreover, the null hypothesis of no lack of fit cannot be rejected ( $\mathrm{p}$-value higher than 0.05), which shows that no other predictors are required.

It has been found that, among the input process parameters, water pressure, cutting head traverse speed, abrasive mass flow rate and depth of cut are significant and workpiece rotational speed is insignificant. In addition, second-order terms of water pressure $\left(P^{2}\right)$ and depth of cut $\left(D O C^{2}\right)$, interaction between water pressure and traverse speed $(P \times u)$, water pressure and depth of cut $(P \times D O C)$, abrasive mass flow rate and depth of cut $\left(\mathrm{m}_{\mathrm{a}} \times D O C\right)$ and between traverse speed and depth of cut $(u \times D O C)$ are significant. The higher the $\mathrm{p}$ value, the less significant the parameter is, hence, the interaction effect of abrasive mass flow rate and depth of cut places as the last of the significant effects. The other terms ( $p$-value $>$ $0.05)$ can be assumed to be insignificant.

Table 3 ANOVA table for the regression model of geometrical error

\begin{tabular}{lccccccc}
\hline Source & DF & Seq SS & Adj SS & $\begin{array}{c}\text { Adj } \\
\text { MS }\end{array}$ & F & P & $\begin{array}{c}\text { Percent } \\
\text { contribution }\end{array}$ \\
\hline Regression & 20 & 183.156 & 183.156 & 9.1578 & 28.07 & 0.000 & 94.76 \\
\hline Linear & 5 & 156.116 & 156.116 & 597.69 & 95.69 & 0.000 & 80.77 \\
$\boldsymbol{P}$ & 1 & 49.357 & 49.357 & 49.3566 & 151.27 & 0.000 & 25.54 \\
$\boldsymbol{m}_{\boldsymbol{a}}$ & 1 & 8.428 & 8.428 & 8.4281 & 25.83 & 0.000 & 4.36 \\
$\boldsymbol{u}$ & 1 & 48.888 & 48.888 & 48.8877 & 149.83 & 0.000 & 25.29 \\
$\boldsymbol{N}$ & 1 & 0.314 & 0.314 & 0.3136 & 0.96 & 0.334 & 0.16 \\
$\boldsymbol{D} \boldsymbol{O C}$ & 1 & 49.130 & 49.130 & 49.1296 & 150.57 & 0.000 & 25.42 \\
\hline
\end{tabular}




\begin{tabular}{|c|c|c|c|c|c|c|c|}
\hline Square & 5 & 4.413 & 4.413 & 0.8826 & 2.71 & 0.039 & 2.28 \\
\hline$P^{2}$ & 1 & 1.758 & 1.782 & 1.7822 & 5.46 & 0.026 & 0.9 \\
\hline$\dot{m}_{a}{ }^{2}$ & 1 & 0.022 & 0.028 & 0.0281 & 0.09 & 0.771 & 0.01 \\
\hline$u^{2 a}$ & 1 & 0.387 & 0.437 & 0.4375 & 1.34 & 0.256 & 0.02 \\
\hline$N^{2}$ & 1 & 0.068 & 0.096 & 0.0958 & 0.29 & 0.592 & 0.03 \\
\hline$D O C^{2}$ & 1 & 2.178 & 2.178 & 2.1784 & 6.68 & 0.015 & 1.13 \\
\hline Interaction & 10 & 22.627 & 22.627 & 2.2627 & 6.93 & 0.000 & 11.70 \\
\hline $\boldsymbol{P} \times \dot{\boldsymbol{m}}_{\boldsymbol{a}}$ & 1 & 0.631 & 0.631 & 0.6308 & 1.93 & 0.174 & 0.33 \\
\hline$P \times u$ & 1 & 4.685 & 4.685 & 4.6855 & 14.36 & 0.001 & 2.42 \\
\hline$P \times N$ & 1 & 0.338 & 0.338 & 0.3379 & 1.04 & 0.317 & 0.17 \\
\hline$P \times D O C$ & 1 & 8.305 & 8.305 & 8.3049 & 25.45 & 0.000 & 4.3 \\
\hline$\dot{m}_{\boldsymbol{a}} \times \mathbf{u}$ & 1 & 1.102 & 1.102 & 1.1017 & 3.38 & 0.076 & 0.57 \\
\hline$\dot{m}_{a}^{a} \times \mathbf{N}$ & 1 & 0.263 & 0.263 & 0.2634 & 0.81 & 0.376 & 0.14 \\
\hline$\dot{m}_{a}^{a} \times \mathrm{DOC}$ & 1 & 1.536 & 1.536 & 1.5363 & 4.71 & 0.038 & 0.85 \\
\hline$u \times N$ & 1 & 0.202 & 0.202 & 0.2021 & 0.62 & 0.437 & 0.8 \\
\hline$u \times D O C$ & 1 & 5.547 & 5.547 & 5.5474 & 17.00 & 0.000 & 2.87 \\
\hline$N \times D O C$ & 1 & 0.017 & 0.017 & 0.0169 & 0.05 & 0.821 & 0.01 \\
\hline Residual Error & 31 & 10.115 & 10.115 & 0.3263 & - & - & 5.23 \\
\hline Lack-of-Fit & 22 & 7.925 & 7.925 & 0.3602 & 1.48 & 0.278 & - \\
\hline Pure Error & 9 & 2.190 & 2.190 & 0.2433 & - & - & - \\
\hline Total & 51 & 193.270 & - & - & - & - & 100 \\
\hline
\end{tabular}

Note: $\mathrm{R}^{2}=0.9477$ (correct?)

As shown in Figure 5, the obtained model accurately fits the experimental data. Upon this, the final model for geometrical error is given in Eq. 5.

$G E=$

$3.99068-1.11082 P-0.459024 \dot{m}_{a}+1.10553 u-0.0885504 N+1.10826 D O C+0.232157 P^{2}+$ $0.0291362 \dot{m}_{a}{ }^{2}+0.115022 u^{2}+0.0538237 N^{2}-0.256667 D O C^{2}-0.140400 P . \dot{m}_{a}-0.382651 P . u+$ 0.102764 P. $N-0.509438$ P.DOC $-0.185551 \dot{m}_{a} \cdot u+0.0907299 \dot{m}_{a} . N-0.219108 \dot{m}_{a} . D O C+$ $0.0794624 u . N+0.41636 u . D O C+0.0229939$ N.DOC

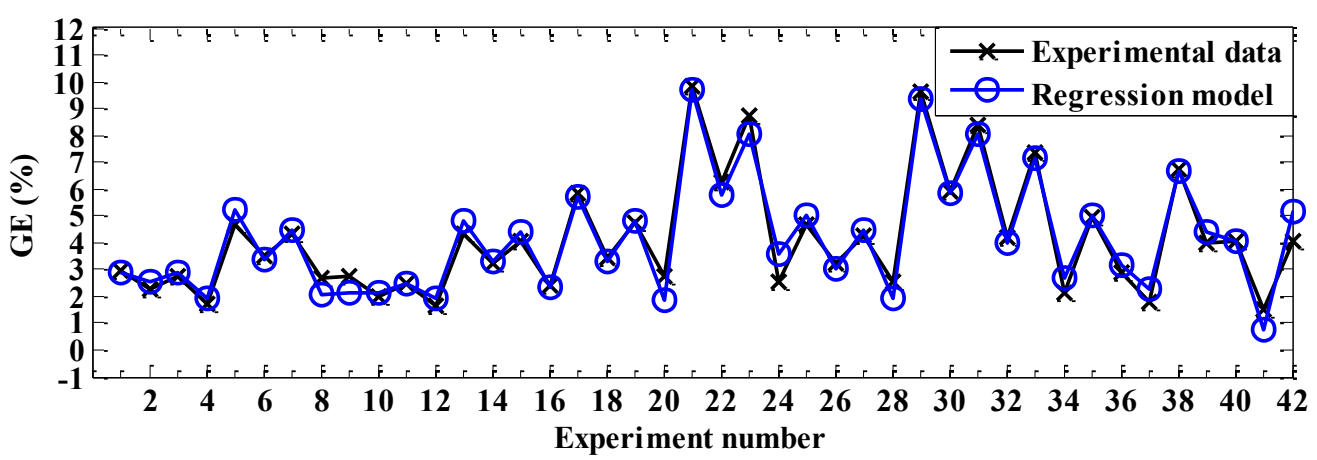

Figure 5 Predicted values vs. experimental data

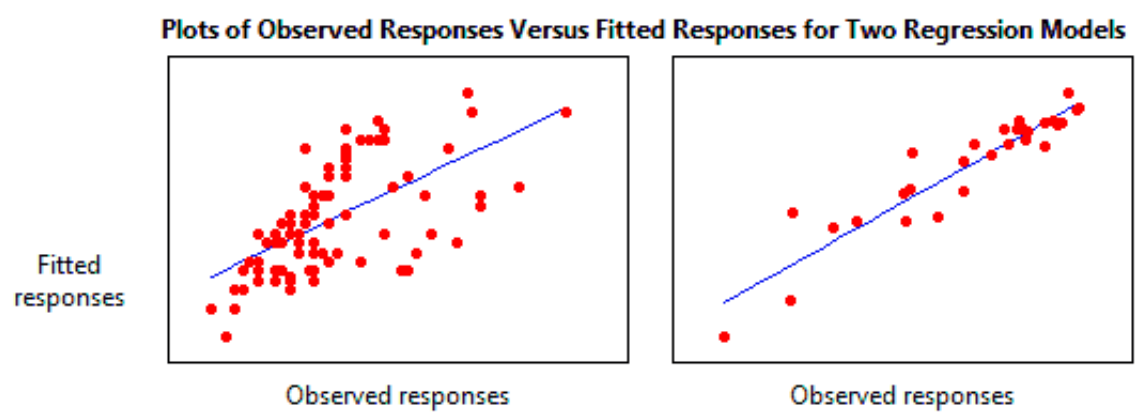

To evaluate the fitting adequacy of the model, the coefficient of determination $\mathrm{R}^{2}$ has been calculated. The $\mathrm{R}^{2}$ value indicates that $94.77 \%$ of the total deviations in the process response 
can be explained by the model. Since the $\mathrm{R}^{2}$ approaches unity, the model fits the experimental data accurately ${ }^{23}$.

\subsection{Effects of the process parameters on geometrical error}

Percent contributions of the model effects have been calculated from their sequential sum of squares (Seq SS) from Table 3 and are graphically shown in Figure 6. It illustrates that, among process parameters, water pressure, cutting head traverse speed and depth of cut are the most influential parameters on controlling the part geometrical error and the abrasive mass flow rate places as the least influential parameter with a percent contribution less than $1 \%$. As the workpiece rotational speed did not have any significant influence on AWJT results in the tested ranges, it was excluded from further consideration in the present paper.

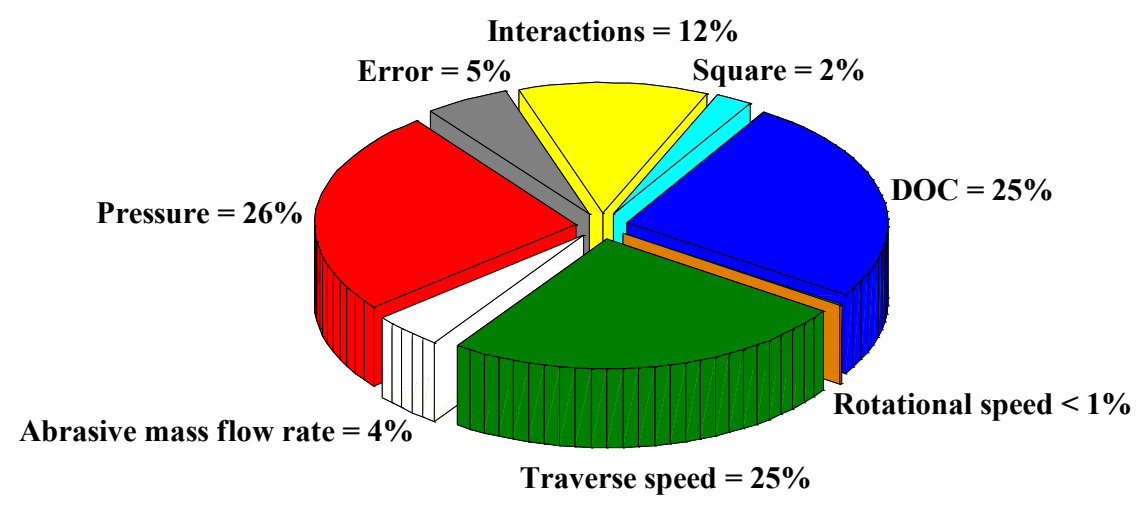

Figure 6 Percent contribution of model effects on the geometrical error

Response contour plots of the geometrical error are illustrated basing on the response regression equation in coded factors (Eq. X). Effects of two significant factors are investigated simultaneously while other factors are kept constant at their middle levels.

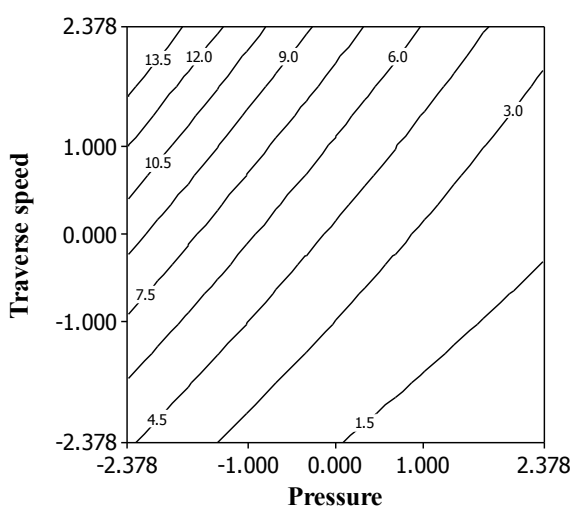

Figure 7 Effect of pressure and traverse speed on the geometrical error $\left(m_{a}=5.24 \mathrm{~g} / \mathrm{s}, D O C=3 \mathrm{~mm}\right.$ and $\left.N=400 \mathrm{rpm}\right)$

Figure 7 shows the contour plot of the geometrical error response with respect to the water pressure and the workpiece traverse speed at constant levels of workpiece rotational speed $(400 \mathrm{rpm})$, abrasive mass flow rate $(5.24 \mathrm{~g} / \mathrm{s})$ and depth of cut $(3 \mathrm{~mm})$. It illustrates that a geometrical error reduction is generally obtainable by decreasing the workpiece traverse speed and increasing the water pressure. An increase of the traverse speed causes a decrease of the exposure time to the jet action. Less abrasive particles impact the surface and the removed volume from the periphery of the workpiece decreases. According to Bernoulli's law and the momentum transfer from water to the abrasives, higher pressures produce more energy and more acceleration of abrasive particles. This condition results in higher erosion rate during the limited exposure time and reduces the workpiece diameter more. 

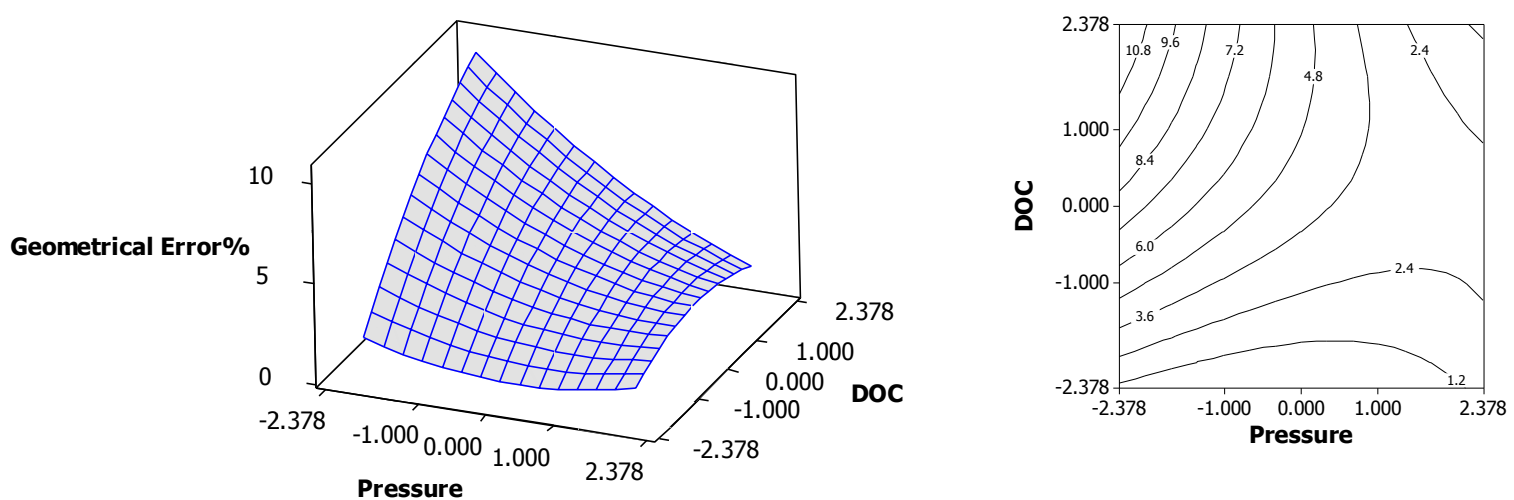

Figure 8 Effect of pressure and depth of cut on the geometrical error $\left(m_{a}=5.24 \mathrm{~g} / \mathrm{s}, u=5 \mathrm{~mm} / \mathrm{min}\right.$ and $\left.N=400 \mathrm{rpm}\right)$

Figure 8 displays 3D surface and contour plot of the geometrical error response in relation to the water pressure and depth of cut while other parameters are kept constant at their middle levels. The opposite effect of depth of cut and pressure on geometrical error is noticeable in the hyperbolic paraboloid (saddle) response surface. Higher depth of cut results in higher geometrical error due to more material to erode ${ }^{2}$ and jet instability ${ }^{10,29}$. Higher pressures reduce the geometrical error as discussed for Figure 7. At the saddle point, the effect of each parameter compensates the opposite effect of the other one. In this condition, keeping the water pressure constant and increasing or decreasing the depth of cut leads to reduction of the geometrical error. This fact happens because during the machining, the initial set DOC is gradually decreased (what do you mean?). In turning at high depths of cut, if the jet energy is high enough (high pressures), it is possible to turn the workpiece until reaching a similar condition to turning at low depths of cut. Thus, produced parts at high and low depths of cut have almost same geometrical error. Instead, if the water pressure decreases, it is not sufficient to efficiently erode the whole material volume. So, increasing $D O C$ at low pressures increases the geometrical error.

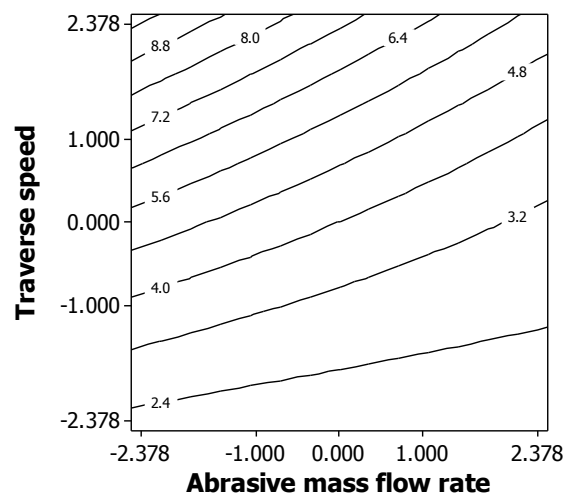

Figure 9 Effect of abrasive mass flow rate and traverse speed on the geometrical error $(P=250 \mathrm{MPa}, D O C=3 \mathrm{~mm}$ and $N=400 \mathrm{rpm})$

Effects of abrasive mass flow rate and traverse speed on the geometrical error are illustrated as contour plot in Figure 9. It is concluded that lower geometrical error is achievable at high abrasive mass flow rates and low traverse speeds. Additionally, at high traverse speeds, the effect of abrasive mass flow rate on reducing the geometrical error is higher than when machining at low workpiece traverse speeds. Similar results were reported by Ansari ${ }^{2}$. 


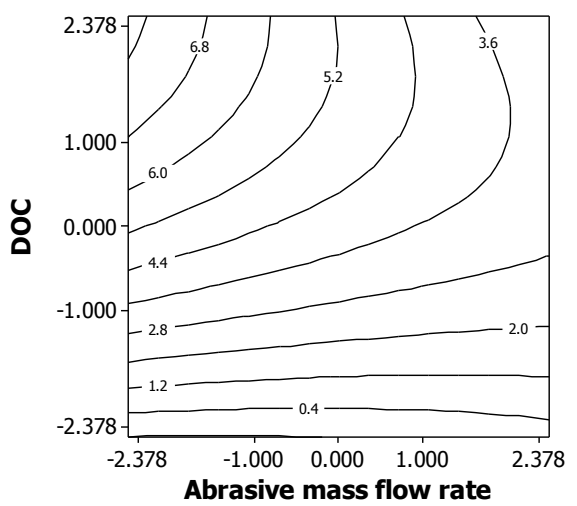

Figure 10 Effect of abrasive mass flow rate and depth of cut on the geometrical error $(P=250 \mathrm{MPa}, u=5 \mathrm{~mm} / \mathrm{min}$ and $N=400 \mathrm{rpm})$

The simultaneous effects of abrasive mass flow rate and depth of cut are depicted in Figure 10. In agreement with the previous research by Ansari ${ }^{2}$, increasing abrasive mass flow rate and decreasing depth of cut reduce the geometrical error. It is worth noting that increasing the abrasive mass flow rate while machining at low depths of cut does not have a meaningful effect on the geometrical error. It means that the material that must be eroded is low enough that higher abrasive mass flow rate cannot be effectively used in the material removal.

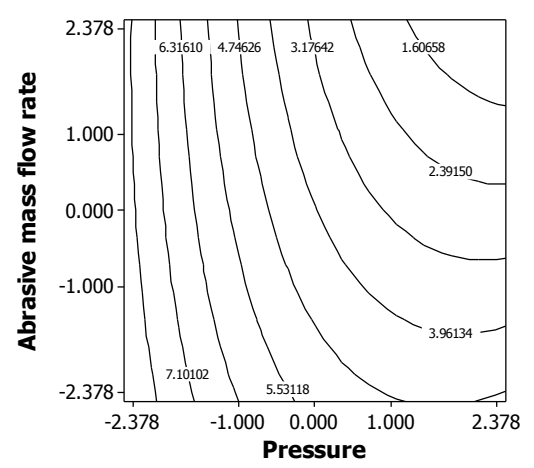

Figure 11 Effect of pressure and mass flow rate on the geometrical error $(D O C=3 \mathrm{~mm}, u=5 \mathrm{~mm} / \mathrm{min}$ and $N=400 \mathrm{rpm})$

Effects of pressure and abrasive mass flow rate on the geometrical error, while other parameters are kept constant, are demonstrated in Figure 11. Increasing pressure and abrasive mass flow rate leads to a reduction of the geometrical error. At low pressures, variations of abrasive mass flow rate almost have no effect on the geometrical error while, at high pressures, abrasive particles are accelerated enough to turn the part with closer tolerances. These findings confirm the previous investigations by Ansari and Hashish ${ }^{2,3,30}$.

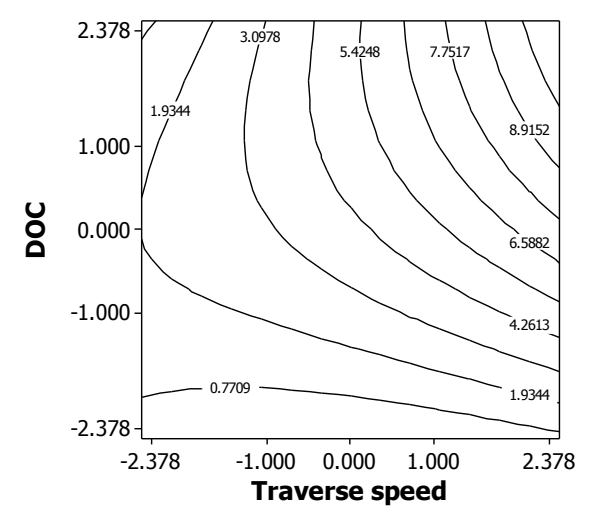

Figure 12 Effect of traverse speed and depth of cut on geometrical error $\left(P=250 \mathrm{MPa}, \boldsymbol{m}_{\boldsymbol{a}}=5.24 \mathrm{~g} / \mathrm{s}\right.$ and N $\left.=400 \mathrm{rpm}\right)$ 
Figure 12 shows contour plot of the geometrical error response with respect to traverse speed and depth of cut at constant levels of pressure, abrasive mass flow rate and rotational speed. It illustrates that for higher depths of cut decreasing traverse speed can highly reduce geometrical error. However, decreasing traverse speed increases the time of machining. In practice turning parts at low depth of cut and high traverse speed in multi passes can be a practical way to increase the process efficiency.

\section{Conclusions}

An experimental study was conducted to investigate the effects of major process parameters and their interaction on geometrical error in abrasive waterjet turning. A five-level experimental design was carried out based on central composite rotatable design. The main effects of parameters and also the interaction between them were analyzed based on an analysis of variance. It is found that among the input process parameters, pressure, abrasive mass flow rate, traverse speed and depth of cut are significantly effective while workpiece rotational speed has not so significant effect on the geometrical error of AWJ turned parts. Pressure, traverse speed and depth of cut were detected as the most significant parameters with almost the same percentage of contribution. Workpiece rotational speed is the least significant parameter. In addition, interactions between pressure and traverse speed, pressure and depth of cut, abrasive mass flow rate and depth of cut and between traverse speed and depth of cut were found to be significant. Besides, a mathematical model for relationship between the process parameters and geometrical error response has been presented based on a quadratic regression. The model could successfully predict the geometrical error of AWJ turned parts.

The presented study activates a potential to improve the precision of abrasive waterjet turning. This requires further investigations to examine reducing geometrical error in relation to improvement of material removal rate and surface quality.

\section{References}

1. Hashish M. Turning with abrasive waterjets - a first investigation. ASME Journal of Engineering for Industry. 1987; 109: 281-90.

2. Ansari AI. A study on turning with abrasive waterjets. Michigan technological University, 1991.

3. Ansari AI, Hashish M. Effect of abrasive waterjet parameters on volume removal trends in turning. ASME Journal of Engineering for Industry. 1995; 117: 475-84.

4. Zhong ZW, Han ZZ. Turning of glass with abrasive waterjet. Material and Manufacturing Processes. 2002; 17: 330-49.

5. Axinte DA, Stepanian JP, Kong MC, McGourlay J. Abrasive waterjet turning-An efficient method to profile and dress grinding wheels. International Journal of MachineTools \& Manufacture. 2009; 49: 351-6.

6. Uhlmann E, Flögel K, Kretzschmar M, Faltin F. Abrasive waterjet turning of high performance materials. 5th CIRP Conference on High Performance Cutting Zürich, Switzerland2012, p. 409-13.

7. Manu R, Babu NR. An erosion-based model for abrasive waterjet turning of ductile materials. Wear. 2009; 266: 1091-7.

8. Kovacevic R, Hashish M, Mohan R, Ramulu M, Kim TJ, Geskin ES. State of the art of research and development in abrasive waterjet machining. ASME Journal of manufacturing Science and Engineering. 1997; 119: 776-85.

9. Mazurkiewicz M. A manufacturing tool for a new century. Journal of Materials Processing Technology. 2000; 106: 112-8.

10. Hashish M, Stewart J. Observations on precision turning with AWJ. 15th International Conference on Jet Cutting Technology. Ronneby, Sweden2000, p. 367-80.

11. Ansari AI, Hashish M, Ohadi MM. Flow visualization study of the macromechanics of abrasive waterjet turning. Experimental Mechanics. 1992; 32: 358-64. 
12. Hashish M. Macro characteristics of AWJ turned surfaces. 2001 WJTA American Waterjet Conference. Minneapolis, Minnesota, USA 2001.

13. Li WY, Wang J, Ali YM. An Experimental Study of Radial-Mode Abrasive Waterjet Turning of Steels. Materials Science Forum. 2012; 697-698 166-70.

14. Henning A. Modeling of turning operation for abrasive waterjets. 10th American Waterjet Conference. Houston, Texas. USA1999.

15. Zohoor M, Zohourkari I. Modeling of Abrasive Waterjet Turning. Australian Journal of Basic and Applied Sciences. 2011; 5: 70-9.

16. Hlavac LM, Palicka P. Testing of parameters for turning by abrasive water jet. 18th International Conference on Water Jetting. Gdansk, Poland2006, p. 123-8.

17. Zohourkari I, Zohoor M. Mathematical Modeling of Abrasive Waterjet Turning of Ductile Materials. The ASME 2010 10th Biennial Conference on Engineering Systems Design and Analysis, ESDA2010. Istanbul, Turkey2010.

18. Manu R, Ramesh Babu N. Influence of jet impact angle on part geometry in abrasive waterjet turning of aluminium alloys. International Journal of Machining and Machinability of Materials. 2008; 3: 120-32.

19. Hlavac LM, Martinec P. Almandine garnets as abrasive material in high energy waterjet physical modelling of interaction, experiment and prediction. 14th International Conference on Jetting Technology. Brugge, Belgium: BHR Group, 1998, p. 211-23.

20. Hlavac LM, Hlavacova IM, Vasek J. Milling of materials by waterjets - Acting of liquid jet in the cutting head. Transactions of the VSB -Technical University of Ostrava, Mechanical Engineering Series. 2007; 53: 73-84.

21. Hlavac L, Vasek J, Hlavacova I, Jandacka P, Madr V. Fracturing of brittle materials in a mixing process with water jet. 17th European Conference on Fracture. Brno, Czech Republic 2008, p. 675-81.

22. Hlavac LM, Hlavacova IM, Jandacka P, et al. Comminution of material particles by water jets Influence of the inner shape of the mixing chamber. International Journal of Mineral Processing. 2010; 95: 259.

23. Montgomery D. Design and analysis of experiments. New York: Wiley, 2009.

24. Lenth RV. Response-surface methods in R, using rsm. Journal of Statistical Software. 2009; 32: 1-17.

25. Myers R, Montgomery D. Response surface methodology. New York: Wiley, 2002.

26. Box GEP, Hunter JS, Hunter WG. Statistics for experimenters. New York: Wiley, 2005.

27. Box GEP, Draper NR. Response surface, mixtures, and ridge analysis. Hoboken: Wiley-Interscience, 2007.

28. Zar JH. Biostatistical Analysis. New Jersey: Prentice Hall International, 1984.

29. Hashish M. Macro characteristics of AWJ turned surfaces. 2001 WJTA American Waterjet Conference. Minneapolis, Minnesota, USA2001, p. 1-14.

30. Hashish M. The effect of pressure on the performance of abrasive waterjet (AWJ) machining. Symposium on Product and Process Design, ASME Manufacturing International. Atlanta, USA1988, p. 255-63. 